Research Article

\title{
Phytochemical, Antimicrobial, and Antioxidant Profiles of Duranta erecta L. Parts
}

\author{
Shadrack Donkor $\mathbb{D}^{1,2}$ Christopher Larbie ${ }^{10},^{2}$ Gustav Komlaga ${ }^{10},^{3}$ \\ and Benjamin Obukowho Emikpe ${ }^{4,5}$ \\ ${ }^{1}$ Applied Radiation Biology Centre, Radiological and Medical Sciences Research Institute, Ghana Atomic Energy Commission, \\ Legon, Accra, Ghana \\ ${ }^{2}$ Department of Biochemistry and Biotechnology, Kwame Nkrumah University of Science and Technology (KNUST), \\ Kumasi, Ghana \\ ${ }^{3}$ Department of Pharmacognosy, Kwame Nkrumah University of Science and Technology (KNUST), Kumasi, Ghana \\ ${ }^{4}$ Department of Veterinary Pathology, University of Ibadan, Ibadan, Nigeria \\ ${ }^{5}$ Department of Pathobiology, School of Veterinary Medicine, Kwame Nkrumah University of Science and Technology (KNUST), \\ Kumasi, Ghana
}

Correspondence should be addressed to Shadrack Donkor; shadrachdonkor2000@gmail.com

Received 18 February 2019; Revised 8 August 2019; Accepted 19 September 2019; Published 24 October 2019

Academic Editor: Ziad Fajloun

Copyright ( 12019 Shadrack Donkor et al. This is an open access article distributed under the Creative Commons Attribution License, which permits unrestricted use, distribution, and reproduction in any medium, provided the original work is properly cited.

\begin{abstract}
The use of plant-based medicine is popular amongst individuals and communities in developing countries. Duranta erecta has been used in Africa and Asia to treat a wide range of diseases. This study evaluated the phytochemical profile and antioxidant and antimicrobial activities of $D$. erecta to ascertain its health benefits in traditional medicine. Phytochemical constituents and antimicrobial effect of the hydroethanolic extract of $D$. erecta leaves (DRL), unripe fruits (DRU), and ripe fruits (DRR) were investigated by standard methods. Elemental analyses were carried out by atomic absorption spectroscopy (AAS) on the raw sample and extract. FTIR and UV-VIS spectroscopy were used to identify functional groups. Extracts were screened for their possible antioxidant activities by three tests. The total phenolic and total tannin contents were evaluated by using the FolinCiocalteu method. Total flavonoid content was determined by the aluminium chloride colorimetric assay method. The antioxidant activities were evaluated using the DPPH scavenging activity. The results of phytochemical screening showed the presence of triterpenoids, sterols, alkaloids, flavonoids, saponins, glycosides, and tannins. FTIR analysis revealed the presence of alcohols, phenols, alkanes, aldehydes, ketones, aromatics, aliphatic amines, aromatic amines, amides, carboxylic acids, esters, nitro compounds, alkynes, primary and secondary amines, and alkyl halides. Iron, zinc, and copper were also detected. Total phenolic and tannin contents ranged from $2.20 \pm 0.15$ to $14.54 \pm 0.29 \mathrm{mg}$ gallic acid equivalent (GAE)/100 g and $3.55 \pm 0.07$ to $13.82 \pm 0.04 \mathrm{mg} \mathrm{GAE} / 100 \mathrm{~g}$, respectively. Total flavonoid content varied from $41.76 \pm 0.96$ to $343.49 \pm 3.45 \mu \mathrm{g}$ quercetin equivalent $(\mathrm{QE}) / 100 \mathrm{~g}$. The highest DPPH scavenging activity was recorded in the methanolic fraction of the leaves. The antimicrobial assay of the extract or fractions recorded no activity against the test organisms. The outcome of this study affirmed that $D$. erecta contains phytochemicals and bioactive compounds that could be of health benefit.
\end{abstract}

\section{Introduction}

The use of medicinal plants has become popular amongst individuals and communities in developing countries. There has been an upsurge in the use of herbal medicines because they are affordable, accessible, culturally acceptable, and effective and supposedly have lesser side effects as compared with synthetic drugs found in Africa [1]. Plants produce various bioactive compounds which contain components of therapeutic value making them a rich source of medicines. Approximately, 25\% of prescription drugs dispensed in the United States are derived from plant sources [2]. The various components confer specific distinctiveness and properties to plants. 
In folk medicine, plants are important source of natural remedies used to treat many diseases. Overdependence on traditional folk medicine has brought to light the issue of sustaining our fast-degrading forest. In Ghana, most of the traditional medicine practitioners depend on our forests for their trade, while our backyards are overgrown with ornamental plants which are equally good source of herbal medicine. Thus, if we want to conserve our forest for sustainable development, then there is the need to screen ornamental plants for biological and pharmacological properties by researchers. This is part of studies identifying alternative use for ornamental plant [3].

Durantabelongs to the Verbenaceae family and it comprises 35 species. It is a native plant of Asia, Africa, and South and Central America [4]. Duranta erecta (synonymous to $D$. repens), commonly known as "golden dew drop," is an upright scrambling shrub with a height of 1$3 \mathrm{~m}$. It is grown as a hedge or ornamental plants in various homes in Ghana. Phytoconstituents including coumarinolignoids, (E)-cinnamic acid, (E)-p-methoxycinnamic acid, and lamiide have been isolated from the genus Duranta $[5,6]$. A number of bioactive compounds such as $\beta$-sitosterol, naringenin, acteoside, lamiide, sucrose, and raffinose have been identified and isolated from Duranta repens [7]. Different parts of the plant are used to treat variety of diseases. The fruit and leaves are used in traditional folk medicine for the treatment of malaria, intestinal worms, and abscess and, in some cases, serve as vermifuge or diuretic. D. erecta is said to possess antitumor activity and significant antibacterial activity [8]. It has numerous natural uses including antifungal and insecticidal properties [9]. The ethyl acetate extract of leaves reportedly exhibited significant antiplasmodial activity against the chloroquinesensitive and chloroquine-resistant strains of Plasmodium falciparum [5]. Methanolic extracts of different parts such as leaves, stem, and roots of D. erecta exhibited antifungal properties against Aspergillus flavus, Alternaria sp., Penicillium sp., Rhizopus sp., and Trichoderma sp., [10]. The aim of the current study was to carry out the phytochemical and antioxidant screening of $D$. erecta grown as hedges in Ghana as a justification for its use in traditional medicine.

\section{Materials and Methods}

2.1. Chemicals. Folin-Ciocalteu phenol reagent (FCR); gallic acid; 2, 2-diphenyl ${ }^{-1}$-picrylhydrazyl hydrate (DPPH); quercetin; ascorbic acid; and DMSO were from Sigma. $\mathrm{AlCl}_{3}, \mathrm{Na}_{2} \mathrm{CO}_{3}, \mathrm{CH}_{3} \mathrm{COOK}, \mathrm{HClO}_{4}, \mathrm{CHCl}_{3}, \mathrm{NaOH}, \mathrm{FeCl}_{3}$, and $\mathrm{NaCl}$ were from Merck (Darmstadt, Germany). Ethanol, methanol, petroleum ether, ethyl acetate, nitric acid, and sulphuric acid were from Janssen Chimica (Beerse, Belgium). Nutrient agar, Mueller-Hinton agar, and chloramphenicol were procured from Oxoid, England. All chemicals were of analytical grade.

2.2. Plant Collection and Authentication. Plant materials (leaves, ripe, and unripe fruits) were collected from KNUST campus in October 2017 and authenticated by Dr. George
Sam at the Department of Herbal Medicine, Faculty of Pharmaceutical Sciences, KNUST, and the specimen was deposited in the faculty's herbarium (voucher number KNUST/HM1/2017/L011).

2.3. Preparation and Extraction of Plant Material. The leaves and fruits of $D$. erecta were washed under running tap water to remove dust and other extraneous substances. They were subsequently dried under shade for 4 weeks. The shade-dried parts of the plant were coarsely powdered using a grinder (Waring, USA). $60 \mathrm{~g}$ of the pulverized samples were extracted with $50 \%$ ethanol by cold maceration for 48 hours at room temperature on a shaker (Rocking Laboratory Shaker). The mixture was separated by centrifugation, and each supernatant was evaporated under reduced pressure using a rotary evaporator (Buchi R-205, Switzerland). The extracts were dried using a vacuum freeze dryer (Heto PowerDry LL3000, UK) to obtain the respective crude extracts which included $D$. erecta leaves and unripe and ripe fruits. $15 \mathrm{~g}$ of each crude extract was sequentially extracted with solvents of increasing polarity starting with petroleum ether, followed by ethyl acetate and methanol. The residual portion was designated as hydro fraction. The various fractions, namely, petroleum ether, ethyl acetate, methanol, and hydro fractions were all air-dried at room temperature and used for the tests.

2.4. Phytochemical Screening. The powdered samples of $D$. erecta leaves, unripe and ripe fruits, and respective crude extracts were subjected to qualitative analysis for identification of tannins (Gelatin test), glycosides (Molisch's test), alkaloids (Dragendorff's reagents), coumarins $\left(\mathrm{FeCl}_{3}\right.$ test), saponins (foam test), flavonoids (alkaline reagent), triterpenoids (Salkowski's test), and sterols (LiebermannBurchard test) according to the standard methods described by Harborne [11] and Sazada et al. [12].

2.5. Heavy Metal Analysis. Prior to sample analysis, the glassware used for the analysis was soaked overnight in $10 \%$ $(\mathrm{v} / \mathrm{v})$ nitric acid, followed by washing with $10 \%(\mathrm{v} / \mathrm{v})$ hydrochloric acid, then rinsed with double-distilled water and dried to eliminate interference. Accurately, $1 \mathrm{~g}$ of each of the extracts and the raw samples were weighed into a $50 \mathrm{~mL}$ digestion tube. Each sample was wet-digested using a mixture of $1 \mathrm{~mL}$ of $\mathrm{H}_{2} \mathrm{O}, 2 \mathrm{~mL}$ of $\mathrm{HCl}, 5 \mathrm{~mL}$ of $1: 1 \mathrm{HNO}_{3}$ : $\mathrm{HClO}_{4}$, and $2 \mathrm{~mL}$ of $\mathrm{H}_{2} \mathrm{SO}_{4}$ for 20 minutes. The mixture was heated in a digestion block at $150^{\circ} \mathrm{C}$. The digested sample was allowed to cool and diluted with $50 \mathrm{~mL}$ of distilled water. The digests were analysed to determine the levels of heavy metals in each extract. Heavy metals including lead, copper, nickel, zinc, and iron were analysed using an atomic absorption spectrometer (Varian AA 240FS) with a long path air acetylene burner and cathode lamp for respective metals.

2.6. UV and FTIR Spectroscopic Analysis. The fractions of leaves and fruits were diluted to $1: 10$ with respective solvents. The fractions were scanned in the wavelength ranging 
from 200 to $700 \mathrm{~nm}$ using a double-beam ultraviolet spectrophotometer (PerkinElmer, USA) to detect the characteristic peaks. $10 \mathrm{mg}$ of the dried extracts was encapsulated in $100 \mathrm{mg}$ of $\mathrm{KBr}$ pellet to prepare translucent sample discs. The powdered sample of each extract was loaded in a FTIR spectroscope (UATR Spectrum 2, PerkinElmer) with a scan range from 400 to $4000 \mathrm{~cm}^{-1}$ and a resolution of $4 \mathrm{~cm}^{-1}$. The peak values of the UV and FTIR were recorded.

2.7. Determination of Total Phenolic Content. The total phenolic content of the fractions was assessed by FolinCiocalteu (FC) procedure [13] with some modifications. Gallic acid was used as the standard. Approximately, $50 \mu \mathrm{L}$ of the extract was mixed with $3 \mathrm{~mL}$ of distilled water and $250 \mu \mathrm{L}$ of FC reagent. The mixture was allowed to stand for 5 minutes, and then $750 \mu \mathrm{L}$ of $20 \% \mathrm{Na} 2 \mathrm{CO} 3$ was added. The resulting mixture was vigorously vortexed for $2 \mathrm{~min}$ and then incubated for $30 \mathrm{~min}$ at room temperature. The absorbance of the solution was measured at $760 \mathrm{~nm}$ using a UV-VIS spectrophotometer ( UV1201, Shimadzu, Japan). All determinations were performed in triplicate. Gallic acid (0.2 mg.mL $\mathrm{mL}^{-1}, 0.4 \mathrm{mg} \cdot \mathrm{mL}^{-1}, 0.6 \mathrm{mg} \cdot \mathrm{mL}^{-1}, 0.8 \mathrm{mg} \cdot \mathrm{mL}^{-1}$, and $1 \mathrm{mg} \cdot \mathrm{mL}^{-1}$ ) was used as standard to prepare a calibration curve from which polyphenolic content in terms of the gallic acid equivalent in one gram of each extract was determined. The total phenolic content was calculated from the calibration curve and final results expressed as mg GAE/100 g DM.

2.8. Determination of Total Flavonoid Content. The aluminium chloride colorimetric assay method [14] was employed to evaluate total flavonoid content (TFC) using quercetin as standard. An aliquot of $500 \mu \mathrm{L}$ of the extract and fractions were mixed with $1.5 \mathrm{~mL}$ of $99.9 \%$ ethanol (EtOH), $100 \mu \mathrm{L}$ of $1 \mathrm{M}$ potassium acetate, $100 \mu \mathrm{L}$ of $10 \%$ aluminium chloride, and $3 \mathrm{~mL}$ of distilled water. The mixture was shaken vigorously and left to stand in dark at room temperature. The resulting mixtures were incubated for $30 \mathrm{~min}$ at room temperature and corresponding absorbance measured at $415 \mathrm{~nm}$. All determinations were carried out in triplicate. A standard calibration curve was constructed using quercetin standard solutions of $20 \mu \mathrm{g} \cdot \mathrm{mL}^{-1}$, $40 \mu \mathrm{g} \cdot \mathrm{mL}^{-1}, \quad 60 \mu \mathrm{g} \cdot \mathrm{mL}^{-1}, \quad 80 \mu \mathrm{g} \cdot \mathrm{mL}^{-1}, \quad 100 \mu \mathrm{g} \cdot \mathrm{mL}^{-1}$, and $120 \mu \mathrm{g} \cdot \mathrm{mL}^{-1} .500 \mu \mathrm{L}$ of each standard was treated in the same manner as the samples above to generate calibration curve. The total flavonoid content of each extract was determined from the curve and the results recalculated and expressed as $\mu \mathrm{g}$ QE/100 g DM.

2.9. Determination of Total Tannins. The amount of tannins in plant extract and fractions was determined by the Folin-Ciocalteu method with slight modifications [13]. $100 \mu \mathrm{L}$ of the sample extract and fractions was added to $5 \mathrm{~mL}$ of distilled water, $500 \mu \mathrm{L}$ of Folin-Ciocalteu reagent, $1 \mathrm{~mL}$ and of $35 \% \mathrm{Na}_{2} \mathrm{CO}_{3}$ solution. The mixture was shaken well and kept at room temperature for $30 \mathrm{~min}$. A set of reference standard solutions of gallic acid $(0.2,0.4,0.6,0.8$, and $\left.1 \mathrm{mg} \cdot \mathrm{mL}^{-1}\right)$ were prepared in the same manner as described earlier. Absorbance for test and standard solutions were measured against the blank at $725 \mathrm{~nm}$ with an UV/Visible spectrophotometer. The total tannin content was determined from the calibration curve, and the results expressed tannin content was in terms of $\mathrm{mg}$ of GAE/100 $\mathrm{g}$ DM.

2.10. Determination of Antioxidant Activity. The free radical scavenging ability of the extracts against DPPH free radical was evaluated as described by Oliveira et al. [15], with some modifications. Briefly, $200 \mu \mathrm{L}$ of each extract was added to $3.8 \mathrm{~mL}$ of $0.004 \% \mathrm{DPPH}$ methanolic solution. After $60 \mathrm{~min}$ of incubation at room temperature in dark, the absorbance was measured at $517 \mathrm{~nm}$. A blank sample containing only methanol was used to zero the spectrophotometer. Each experiment was performed in triplicate.

Inhibition ( $\mathrm{I} \%$ ) was calculated as follows:

$$
I \%=\left[\frac{A b s_{0}-A b s_{1}}{A b s_{0}}\right] * 100,
$$

$A b s_{0}=$ absorbance of $0.004 \% \mathrm{DPPH}$ without analyte,

$A b s_{1}=$ absorbance of $0.004 \%$ DPPH plus the test compound.

2.11. Preparation of Culture Media and Inoculum. The media used in the assay comprised nutrient agar (Oxoid, CM0003, England), bacteriological peptone (Sigma-Aldrich, P0556, Germany), and Mueller-Hinton agar (Oxoid, CM0337, Oxoid Ltd, England). The media were prepared according to the manufacturer's instructions.

2.11.1. Preparation of Inoculum. The assay factored nine bacteria and yeast isolates. The stock cultures of Pseudomonas aeroginosa (ATCC 27853), Escherichia coli (ATCC 25922), Salmonella typhi (ATCC 19430), Staphylococcus aureus (ATCC 25923), Proteus mirabilis (ATCC 49565), Candida albicans, Klebsiella pneumonia (ATCC 33495), Paratyphi B, and Staphylococcus saprophyticus (ATCC 15305) were subcultured onto fresh nutrient agar (Oxoid, CM0003, England) plates to obtain pure colonies. Single colonies of each organism were suspended in test tubes containing $5 \mathrm{~mL}$ of sterilized bacteriological peptone (Sigma-Aldrich, P0556, Germany) and incubated at $37^{\circ} \mathrm{C}$ for 10-18 hours to attain the turbidity of $0.5 \mathrm{McFarland}$ standards [16]. The turbidity of the actively growing broth cultures which were not in conformity to the standard (exceeded the standard) were adjusted with sterile bacteriological peptone to obtain turbidity optically comparable with that of $0.5 \mathrm{McF}$ arland standard (approximately 1$2 \times 108 \mathrm{CFU} / \mathrm{mL}$ for E. coli ATCC 25922) [17].

2.11.2. Preparation of Plant Fractions for the Bioassays. Considering the preparation of stock solutions for the bioassays, $100 \mathrm{mg} \cdot \mathrm{mL}^{-1}, 200 \mathrm{mg} \cdot \mathrm{mL}^{-1}$, and $300 \mathrm{mg} \cdot \mathrm{mL}^{-1}$ of 
the fractionated plant extracts were reconstituted using 20\% v/v DMSO (Sigma, D5879, Germany) resulting in percentage concentrations of $10 \%, 20 \%$, and $30 \%$ for the determination of antimicrobial activity. The crude extract was dissolved in sterile distilled water for the aqueous extract preparation of same concentrations. The stock solutions were stored in a refrigerator until needed.

\subsubsection{Antimicrobial Activity Assay (Agar Diffusion} Method). The antimicrobial activity was carried out using the agar diffusion method [17]. The inoculums were inoculated by swabbing onto sterile Mueller-Hinton agar (Oxoid, CM0337, Oxoid Ltd, England). A sterilized cock borer of an internal diameter of about $4 \mathrm{~mm}$ was used to punch six holes in the medium. The plant extracts were dispensed into the holes to a volume of $100 \mu \mathrm{L}$. The positive control was an antibiotic disc of $30 \mu \mathrm{g}$ chloramphenicol (Oxoid, CT00143 Oxoid Ltd, England), and 20\% v/v DMSO (Sigma, D5879, Germany) was used as negative control in a triplicate fashion. The plates were refrigerated for about $4 \mathrm{~h}$ to allow for absolute diffusion of the extract and incubated at $37^{\circ} \mathrm{C}$ for $24 \mathrm{~h}$, after which the diameter of each zone of inhibition was measured in millimetres $(\mathrm{mm})$ with a sterilized ruler.

2.12. Data Analysis. The results were expressed as mean \pm standard error mean (SEM) and compared by one-way analysis of variance followed by Tukey's multiple comparison test at the $95 \%$ significant level using GraphPad Prism version 6.0.

\section{Results and Discussion}

\subsection{Results}

3.1.1. Phytochemical Constituents. Qualitative phytochemical screening of raw leaves and fruits of $D$. erecta indicated presence of tannins, glycosides, saponins, flavonoids, and triterpenoids. Alkaloids were present in unripe fruits only while coumarins were not detected in any of the parts of $D$. erecta (Table 1).

3.1.2. Heavy Metal Content in D. erecta. The concentration levels of $\mathrm{Ni}$ and $\mathrm{Pb}$ were below detectable limits of $1 \times 10^{-5} \mathrm{mg} \cdot \mathrm{L}^{-1}$ for the leaves and fruits. The highest mean concentration for $\mathrm{Fe}\left(2.17 \pm 0.05 \mathrm{mg} \cdot \mathrm{L}^{-1}\right)$ was found in leaves (raw) and the lowest $\left(0.33 \pm 0.01 \mathrm{mg} \cdot \mathrm{L}^{-1}\right)$ in the ripe fruit extracts (Table 2). The permissible limit of $\mathrm{Fe}$ in medicinal plants is $20 \mathrm{mg} \cdot \mathrm{mL}^{-1}$ [17].

3.1.3. UV-Vis Spectroscopic Analysis. The UV-Vis spectroscopy of extract/fractions of $D$. erecta was done at a range of 200 to $700 \mathrm{~nm}$. The number of peaks and maximum absorption range is shown in Table 3.

3.1.4. FTIR Spectra. The FTIR spectra are shown in Figures 1-3, and these enabled the identification of possible
TABLe 1: Phytochemical constituents of D. erecta.

\begin{tabular}{lccc}
\hline Test & Leaves & Unripe fruits & Ripe fruits \\
\hline Tannins & + & + & + \\
Glycosides & + & + & + \\
Alkaloids & - & + & - \\
Coumarins & - & - & - \\
Saponins & + & + & + \\
Flavonoids & + & + & + \\
Triterpenoids & + & + & + \\
Sterols & + & + & + \\
\hline
\end{tabular}

Note. +, present; -, not detected.

functional groups of the active components present in the fractions of $D$. erecta.

3.1.5. Total Phenolic Content. The total polyphenolic contents varied among the extracts and fractions. The mean highest total phenolic level was observed in the hydro fraction of unripe fruit with a corresponding value of $14.54 \pm 0.29 \mathrm{mg} \mathrm{GAE} / 100 \mathrm{~g}$, whilst the lowest value of $2.20 \pm 0.15 \mathrm{mg}$ GAE/100 $\mathrm{g}$ was recorded in petroleum ether fraction of the leaves. This is presented in Figure 4 .

3.1.6. Total Flavonoid Content. The highest total flavonoid content was observed in ethyl acetate fraction of the leaves $(343.49 \pm 3.45 \mu \mathrm{g} \mathrm{QE} / 100 \mathrm{~g})$. This is followed by hydro fraction of leaves $(338.70 \pm 4.18 \mu \mathrm{g} \mathrm{QE} / 100 \mathrm{~g})$, hydro fraction of unripe fruit $(330.08 \pm 1.92 \mu \mathrm{g} \mathrm{QE} / 100 \mathrm{~g})$, ethyl acetate fraction of unripe fruit $(280.08 \pm 3.45 \mu \mathrm{g} \mathrm{QE} / 100 \mathrm{~g})$, crude extract of unripe seeds $(248.60 \pm 2.25 \mu \mathrm{g} \mathrm{QE} / 100 \mathrm{~g})$, crude extract of ripe seeds $(218.00 \pm 3.45 \mu \mathrm{g} \mathrm{QE} / 100 \mathrm{~g})$, methanolic fraction of ripe seeds $(146.17 \pm 0.96 \mu \mathrm{g} \mathrm{QE} / 100 \mathrm{~g})$, and hydro fraction of unripe seeds (41.76 $\pm 0.96 \mu \mathrm{g} \mathrm{QE} / 100 \mathrm{~g}$ ) (Figure 5).

3.1.7. Total Tannins Content (TTC). The TTC was expressed in terms of gallic acid equivalent per $100 \mathrm{~g}$ of the extract. The TTC varied from $13.82 \pm 0.04 \mathrm{mg}$ GAE/100 $\mathrm{g}$ to $3.55 \pm 0.07 \mathrm{mg} \mathrm{GAE} / 100 \mathrm{~g}$ (Figure 6).

3.1.8. DPPH Free Radical Scavenging Activity. The DPPH free radical scavenging activity was expressed as percentage (\%). The highest scavenging activity of $90.0 \%$ was registered for methanolic fraction of the leaves, whilst the lowest methanolic fraction of 5.4\% was seen in unripe fruit (Figure 7).

3.1.9. Antimicrobial Activity. The antimicrobial activity assay of the ripe fruit, unripe fruit, and leaves of $D$. erecta proved negative for all the crude, hydro, and methanol fractions with no recorded antimicrobial activity against the test organisms. The positive control (standard antibiotic), however, recorded positive responses to the test organisms.

3.2. Discussion. In the present study, we carried out phytochemical investigation on Duranta erecta with the view of determining its usefulness in traditional medicine. The 
TABle 2: Heavy metal content of raw plant materials and extracts.

\begin{tabular}{|c|c|c|c|c|c|}
\hline \multirow{2}{*}{ Material } & \multicolumn{5}{|c|}{ Metals } \\
\hline & $\mathrm{Fe}\left(\mathrm{mg} \cdot \mathrm{L}^{-1}\right)$ & $\mathrm{Zn}\left(\mathrm{mg} \cdot \mathrm{L}^{-1}\right)$ & $\mathrm{Ni}\left(\mathrm{mg} \cdot \mathrm{L}^{-1}\right)$ & $\mathrm{Cu}\left(\mathrm{mg} \cdot \mathrm{L}^{-1}\right)$ & $\mathrm{Pb}\left(\mathrm{mg} \cdot \mathrm{L}^{-1}\right)$ \\
\hline Unripe fruit raw & $1.97 \pm 0.06$ & $0.70 \pm 0.01$ & BDL & $0.04 \pm 0.01$ & $\mathrm{BDL}$ \\
\hline Unripe fruit extract & $0.64 \pm 0.04$ & $0.40 \pm 0.02$ & $\mathrm{BDL}$ & $\mathrm{BDL}$ & $\mathrm{BDL}$ \\
\hline Ripe fruit, raw & $2.03 \pm 0.06$ & $0.64 \pm 0.01$ & $\mathrm{BDL}$ & $0.11 \pm 0.01$ & $\mathrm{BDL}$ \\
\hline Ripe fruit, extract & $0.33 \pm 0.01$ & $0.43 \pm 0.01$ & BDL & BDL & BDL \\
\hline Leaves, raw & $2.17 \pm 0.05$ & $1.35 \pm 0.04$ & BDL & $0.02 \pm 0.01$ & BDL \\
\hline Leaves, extract & $0.96 \pm 0.03$ & $1.26 \pm 0.045$ & $\mathrm{BDL}$ & BDL & $\mathrm{BDL}$ \\
\hline
\end{tabular}

Note. BDL, below detection limit; detection limit, $0.00001 \mathrm{mg} \cdot \mathrm{L}^{-1}$.

TABLE 3: UV-Vis peaks and absorption range.

\begin{tabular}{lcc}
\hline Extract/fractions & $\begin{array}{c}\text { Number of } \\
\text { peaks }\end{array}$ & $\begin{array}{c}\text { Wavelength } \\
\text { range (nm) }\end{array}$ \\
\hline Leaves & 5 & $203.0-268.1$ \\
Petroleum ether fraction & 5 & $204.0-226.0$ \\
Ethyl acetate fraction & 5 & $204.2-215.9$ \\
Methanol fraction & 3 & $285.2-385.1$ \\
Hydro fraction & 2 & $284.0-382.9$ \\
Crude extract & & \\
Unripe & 5 & $205.9-218.1$ \\
Petroleum ether fraction & 5 & $204.0-226.0$ \\
Ethyl acetate fraction & 3 & $203.7-322.3$ \\
Methanol fraction & 5 & $287.1-381.5$ \\
Hydro fraction & 5 & $286.2-4231$ \\
Crude extract & & \\
Ripe & 5 & $203.0-217.3$ \\
Petroleum ether fraction & 5 & $207.0-223.0$ \\
Ethyl acetate fraction & 5 & $201.5-384.1$ \\
Methanol fraction & 4 & $286.9-376.9$ \\
Hydro fraction & 3 & $285.9-379.0$ \\
Crude extract &
\end{tabular}

leaves and ripened fruits contained tannins, glycosides, saponins, flavonoids, and triterpenoids, whilst the unripe fruits contained all the aforementioned in addition to alkaloids (Table 1). The absence of alkaloids in the leaves is not consistent with earlier reports $[9,18]$ that detected an appreciable level of alkaloids in $D$. erecta leaves. Phytochemicals play important role by combining with nutrients and dietary fibre to us against diseases though some have bitter taste. Alkaloids have been shown to have antioxidant properties via alleviating $\mathrm{H} 2 \mathrm{O} 2$-induced oxidative damage [19]. Alkaloids have also been implicated in antimalarial activity of many plants by blocking protein synthesis in Plasmodium falciparum [20]. Tannins are known potent antioxidants, and this activity is achieved by chelation of metal ions such as Fe (II) and interfering with one of the reaction steps in the Fenton reaction thereby retarding oxidation [21]. Saponins possess antioxidant potential through hydrogen peroxide scavenging capability [21]. Flavonoids have the ability to inhibit lipid peroxidation by sugar substitutions in the phenolic $\mathrm{C}$ ring [19]. Triterpenoids and steroid saponins have been found detrimental to $P$. falciparum [19]. This goes to buttress the use of D. erecta in malaria in folk medicine. The presence of these phytochemicals account for their multipurpose in traditional medicine.
The concentration levels of $\mathrm{Ni}$ and $\mathrm{Pb}$ were below detectable limits of $1 \times 10-5 \mathrm{mg} \cdot \mathrm{L}^{-1}$ for the leaves and fruits. The highest mean concentration for Fe $\left(2.17 \pm 0.05 \mathrm{mg} \cdot \mathrm{L}^{-1}\right)$ was found in leaves (raw) and the lowest $\left(0.33 \pm 0.01 \mathrm{mg} \cdot \mathrm{L}^{-1}\right)$ in the ripened fruit extracts (Table 2). The permissible limit of $\mathrm{Fe}$ in medicinal plants is $20 \mathrm{mg} \cdot \mathrm{L}^{-1}$ [22]. The concentration of $\mathrm{Zn}$ in the analysed samples ranged from $1.35 \pm 0.04 \mathrm{mg} \cdot \mathrm{L}^{-1}$ to $0.40 \pm 0.02 \mathrm{mg} \cdot \mathrm{L}^{-1}$. The highest concentration level of $\mathrm{Zn}$ was recorded in the raw leaf samples. These values were within $\mathrm{FAO} / \mathrm{WHO}$ permissible limits of $27.4 \mathrm{mg} \cdot \mathrm{L}^{-1}$ in medicinal plants and were regarded as safe. The concentration of $\mathrm{Cu}$ in the samples varied. The highest $\mathrm{Cu}$ level of $0.11 \pm 0.01 \mathrm{mg} \cdot \mathrm{L}^{-1}$ was observed in ripened fruit, followed by unripe $0.04 \pm 0.01 \mathrm{mg} \cdot \mathrm{L}^{-1}$ and leaves $0.02 \pm 0.01 \mathrm{mg} \cdot \mathrm{L}^{-1}$. The permissible limit of $\mathrm{Cu}$ in plants recommended by WHO is $10 \mathrm{mg} \cdot \mathrm{kg}^{-1}$. In all the analysed samples, concentration of $\mathrm{Cu}$ recorded was below the permissible limit.

The use of medicinal plants for healthcare presents a way to humans to get exposed to trace elements and heavy metals. Major and trace elements have significant roles in combating a variety of human ailments and diseases [23]. Also, beyond certain limits, these may present serious health hazards to humans. The knowledge on minerals and heavy metal content is essential for safe use of medicinal plants. All the elements evaluated were within the WHO/FAO permissible limits. The presence of these elements, and in the appropriate amounts, in the plant confers useful values on this plant. Fe is an important trace element, and iron-protein mixtures play a vital role in metabolism. It is essential in the biosynthesis of haemoglobin and transport of oxygen and electrons throughout the body [24]. Zn is a component of many metalloenzymes, especially enzymes which play a central role in nucleic acid metabolism. It is also essential in bone formation, wound healing, brain development, and normal growth processes [25]. Cu is an essential component of many enzymes, and it plays a significant role in a wide range of physiological processes including Fe utilization, free radical elimination, bone and connective tissues development, and melanin production [24].

The presence of phytochemicals was confirmed by spectroscopic studies showing the characteristic spectra obtained in the ultraviolet and visible spectrum. The UV-Vis spectra of the extracts of the various parts had absorption maxima in the region of $203.0-385.1 \mathrm{~nm}, 202-423.0 \mathrm{~nm}$, and $203.0-379.0 \mathrm{~nm}$ for the leaves, unripe fruits, and ripe fruits, respectively. These absorption bands are characteristic for 


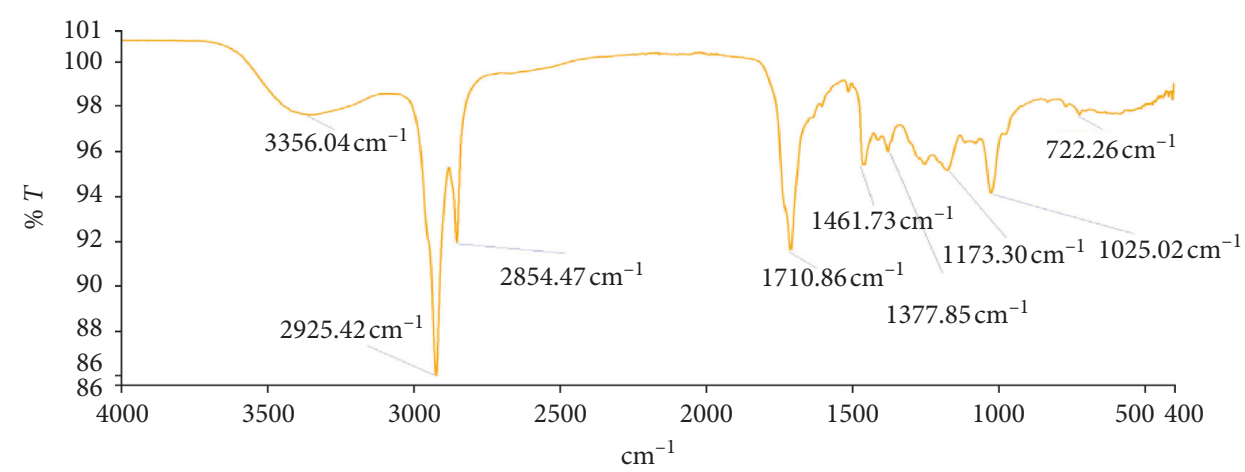

(a)

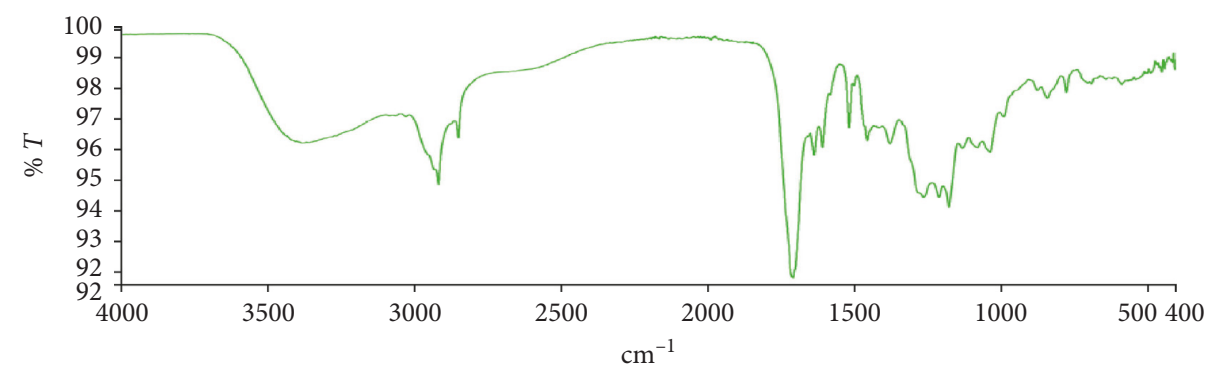

(b)

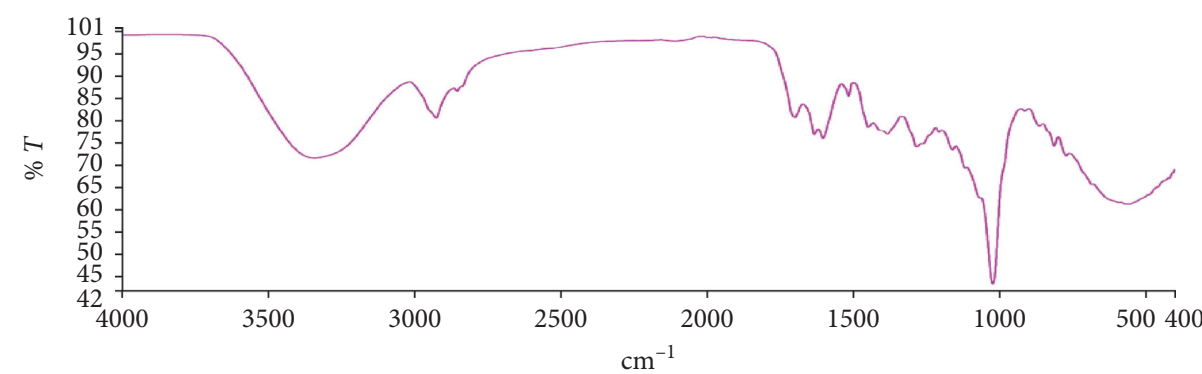

(c)

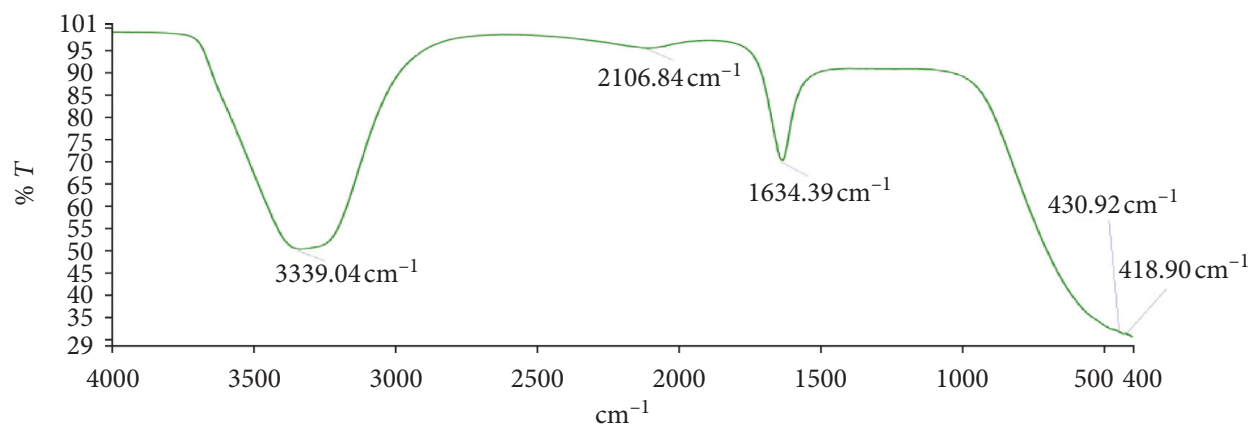

(d)

FIGURE 1: FTIR spectrum of petroleum ether (a), ethyl acetate (b), methanolic fraction (c), and hydro fraction (d) of $D$. erecta leaf extract.

flavonoid and its derivatives. The flavonoid spectra mainly consist of two absorption maxima in the ranges of 230$285 \mathrm{~nm}$ and $300-350 \mathrm{~nm}$ [26]. Similar results were confirmed in an earlier study [27] that reported UV-Vis spectrum of leaf extract in the absorption range of 270 and $340 \mathrm{~nm}$.

The FTIR spectrum was used to establish identity of the functional groups present in extract based on the peak values in the region of infra-red radiation. The results of FTIR analysis revealed the presence of alcohols, phenols, alkanes, aldehydes, ketones, aromatics, aliphatic amines, aromatic amines, amides, carboxylic acids, esters, nitro compounds, alkynes, primary and secondary amines, and alkyl halides (Figures 1-3). These were confirmed by FTIR spectroscopic analysis that predicted the presence of the following groups: $\mathrm{C}-\mathrm{Br}, \mathrm{O}-\mathrm{H}, \mathrm{C}-\mathrm{H}, \mathrm{C}=\mathrm{C}, \mathrm{C}=\mathrm{O}, \mathrm{C} \equiv \mathrm{C}, \mathrm{N}-\mathrm{H}, \mathrm{C}-\mathrm{H}, \mathrm{C}-\mathrm{N}, \mathrm{C}=0$. The presence of the various characteristic functional groups may be responsible medicinal properties of $D$. erecta. 


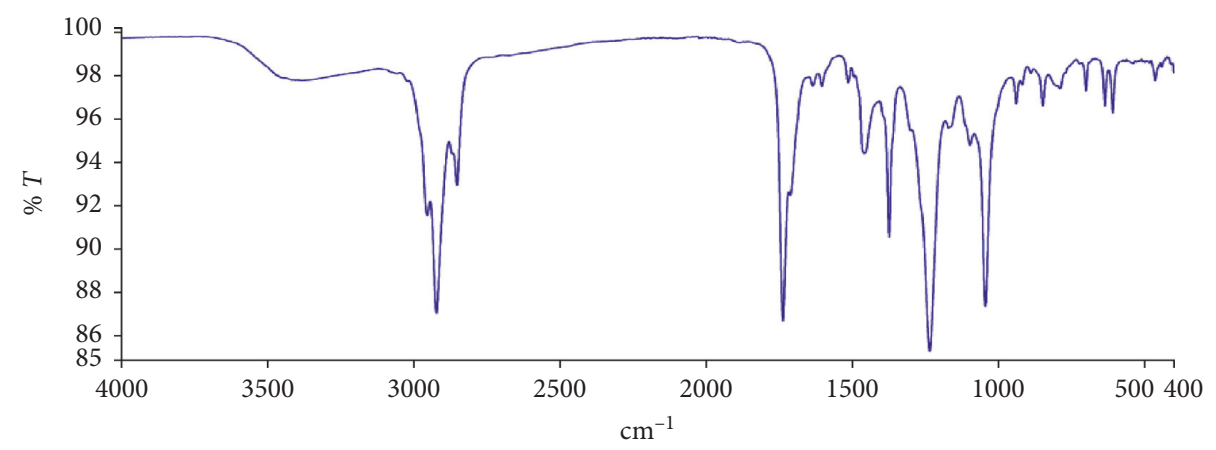

(a)

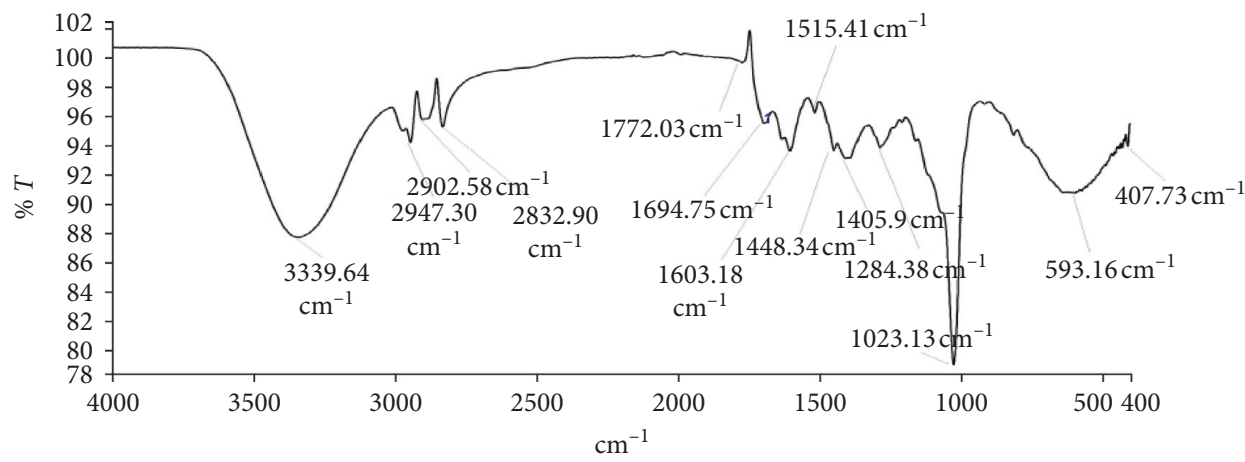

(b)

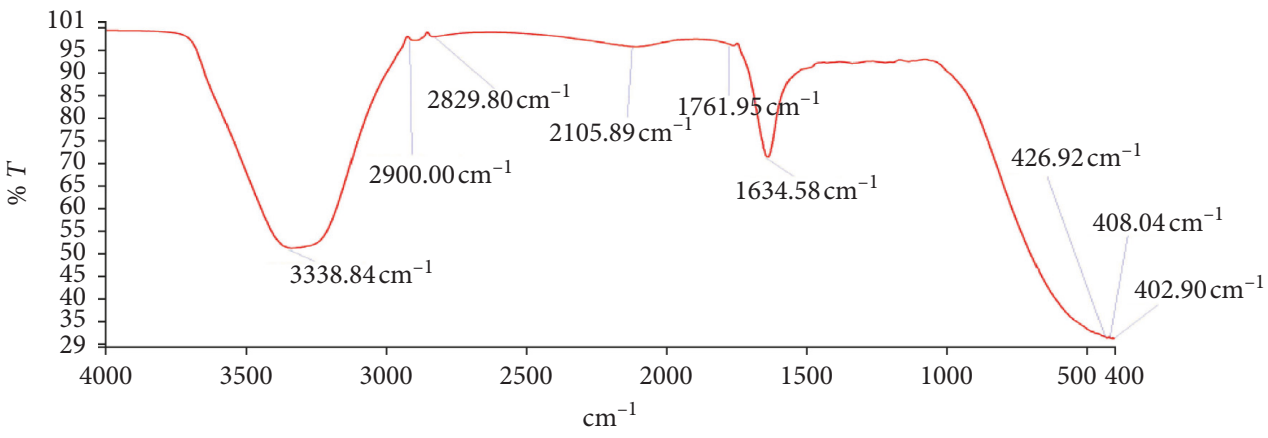

(c)

FIGURE 2: FTIR spectrum of ethyl acetate (a), methanolic fraction (b), and hydro fraction (c) of D. erecta unripe fruit extract.

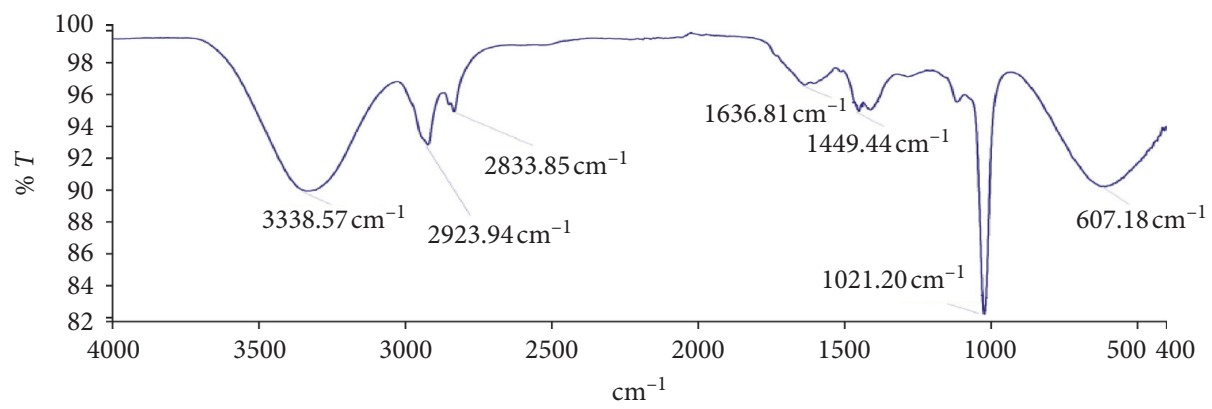

(a)

Figure 3: Continued. 


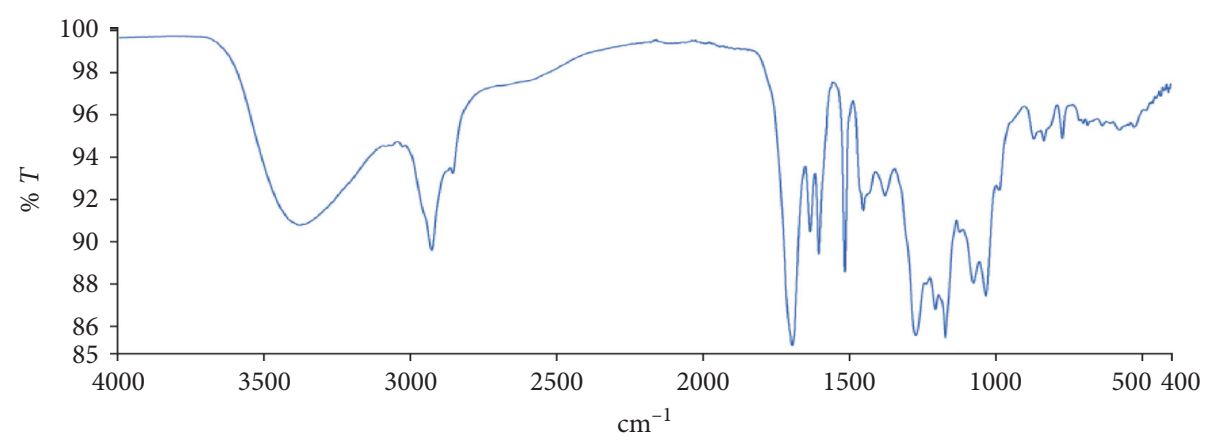

(b)

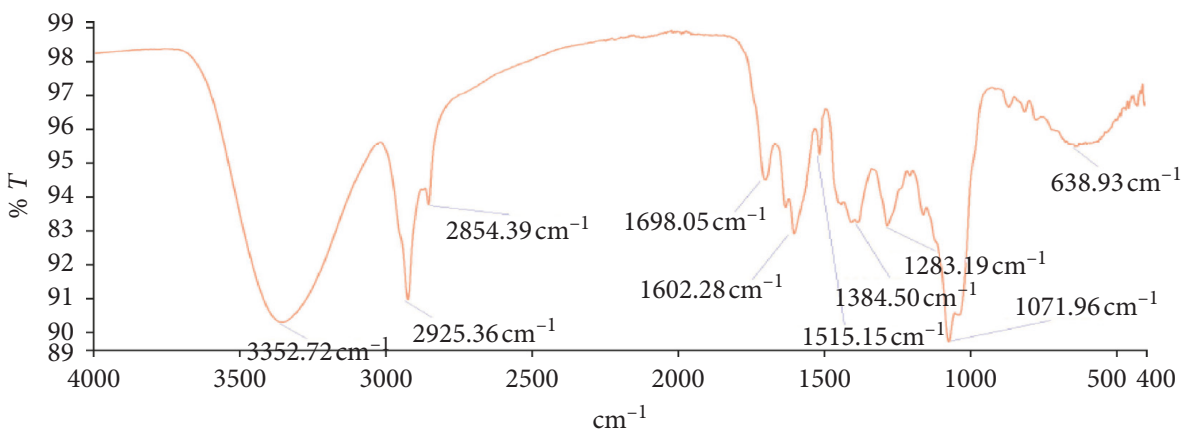

(c)

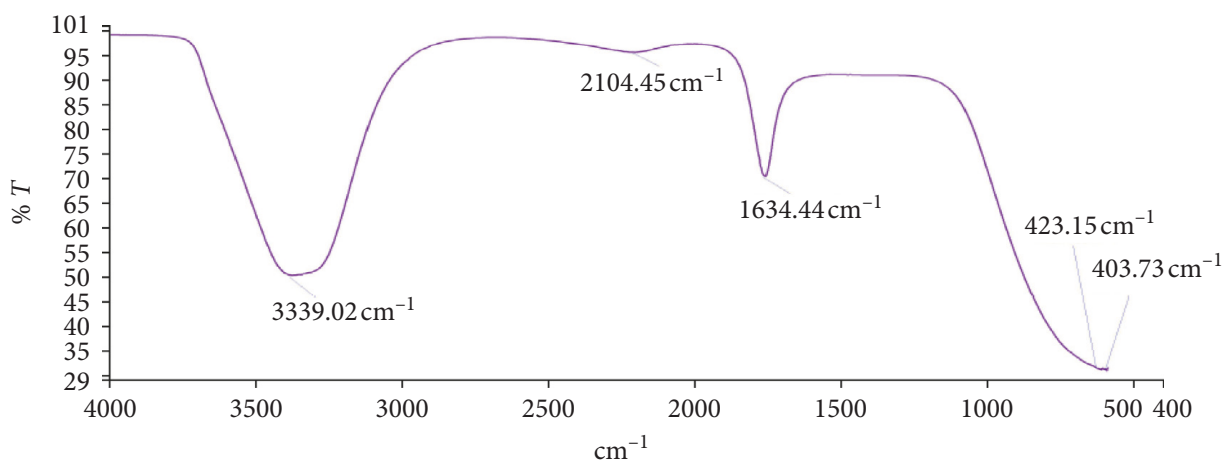

(d)

FIGURE 3: FTIR spectrum of petroleum ether (a), ethyl acetate (b), methanolic (c), and hydro fraction (d) of D. erecta ripe fruit extract.

The hydro fraction of the unripe fruit recorded the highest total phenolic content ( $14.54 \pm 0.29 \mathrm{mg} \mathrm{GAE} / 100 \mathrm{~g})$, whilst the petroleum ether fraction of the leaves exhibited the lowest value $(2.20 \pm 0.15 \mathrm{mg} \mathrm{GAE} / 100 \mathrm{~g}$; Figure 4$)$. The polyphenolic content in the fraction depends on the polarity of the extraction solvent used. High solubility of phenols in polar solvents provides high concentration of these compounds when polar solvent is used in the extraction process [28]. Polyphenolic compounds are important plant constituents due to their scavenging ability. The scavenging ability is by virtue of the hydroxyl groups which has high affinity for hydrogen atom, thereby conferring antioxidative property on the compounds. The mode of action of phenolic compounds in free radical moping activity is by inactivating lipid free radicals or by preventing the decomposition of hydroperoxides into free radicals [29]. The antioxidant property makes such compounds useful in the management of oxidative stress in humans.
From Figure 5, the total flavonoid content varied from $343.49 \pm 3.45 \mu \mathrm{g} \mathrm{QE} / 100 \mathrm{~g}$ to $47 \pm 0.96 \mu \mathrm{g} \mathrm{QE} / 100 \mathrm{~g}$. The highest total flavonoid content was recorded in the ethyl acetate fraction of the leaves and the lowest in the hydro fraction of unripe fruits. The concentration of flavonoids in extract depends on the polarity of solvents and the part of plant material used for extractions [30]. The highest concentration of flavonoids was recorded in solvent of moderate polarity. The antioxidative properties of flavonoids can be linked to several different mechanisms, such as scavenging of free radicals, chelation of metal ions, such as iron and copper, and inhibition of enzymes responsible for free radical generation [29] Flavonoids also possess antibacterial activity. The antibacterial mechanisms of action of selected flavonoids are attributed to inhibition of DNA gyrase, cytoplasmic membrane function and complexing with bacterial cell wall, and licochalcones A and C energy metabolism [31]. 


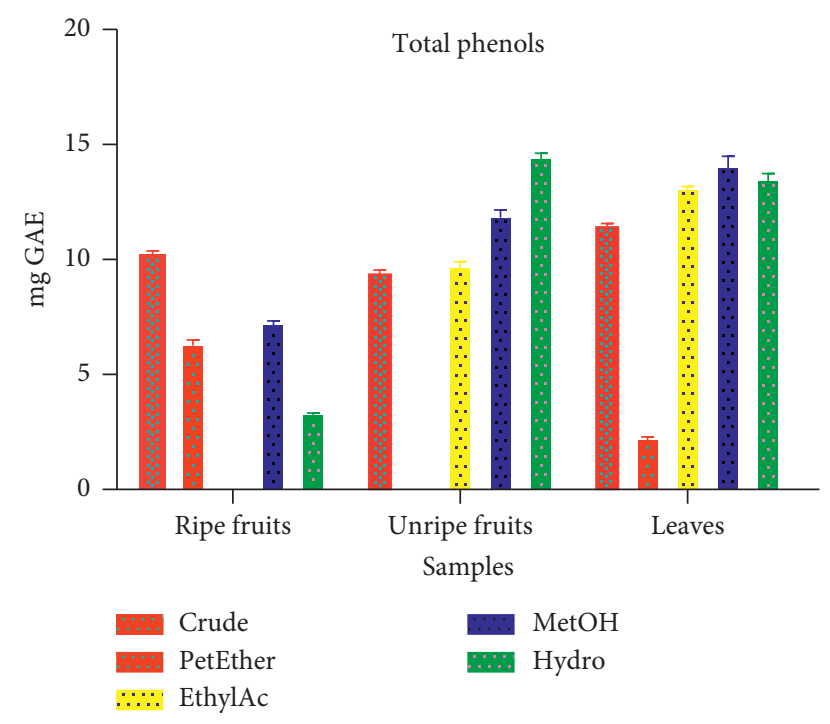

Figure 4: Total phenolic content of extract and fractions of $D$. erecta.

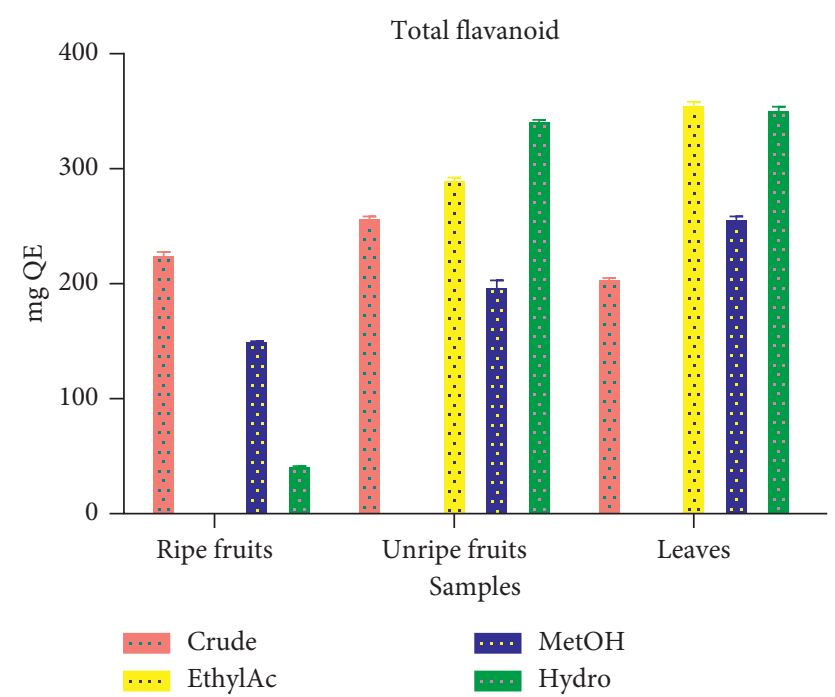

Figure 5: Total flavonoid content of extract and fractions of $D$. erecta.

The crude extract of the leaves recorded the highest concentration of tannins level $13.82 \pm 0.04 \mathrm{mg} \mathrm{GAE} / 100 \mathrm{~g}$, while the least $(3.55 \pm 0.07 \mathrm{mg} \mathrm{GAE} / 100 \mathrm{~g}$ ) was observed in petroleum ether fraction of the leaves. Comparing our data with a similar work $[22,32]$ done elsewhere in Africa, the current data showed higher tannin levels. The differences could be partly due to climatic conditions and the part of the plant used in the extraction. Tannins inhibit lipid peroxidation by downregulating activity of cyclo-oxygenase enzyme through inflammation pathway. However, tannins interact with protein molecules forming large cross-linked complexes, thereby rendering them indigestible.

DPPH is a stable radical relative to other in vitro-generated free radicals such as hydroxyl radical and superoxide anion. DPPH has an added advantage of being not affected by certain side reactions, such as metal-ion chelation and

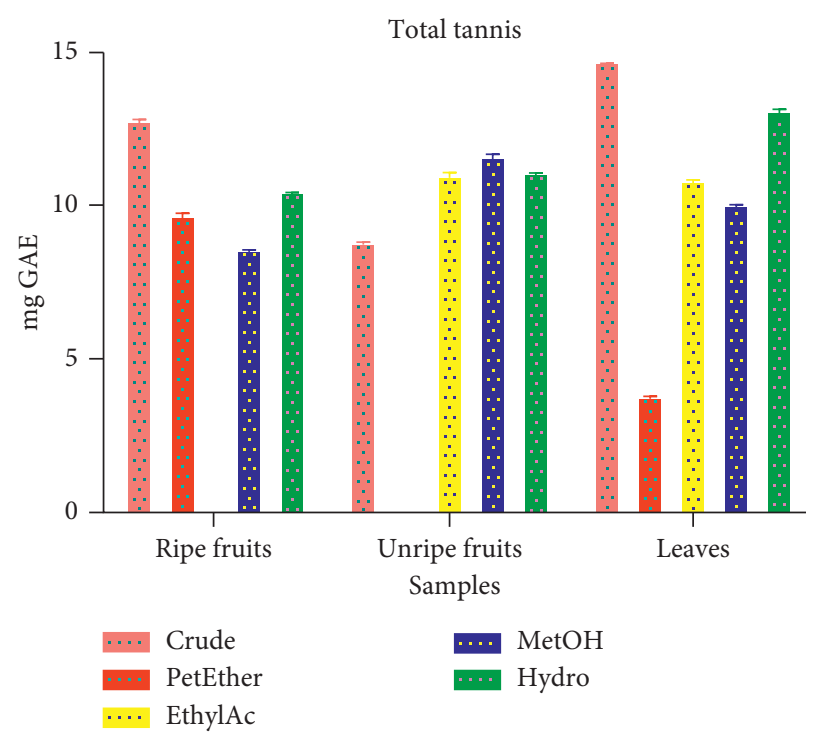

Figure 6: Total tannins content of extract and fractions of $D$. erecta.

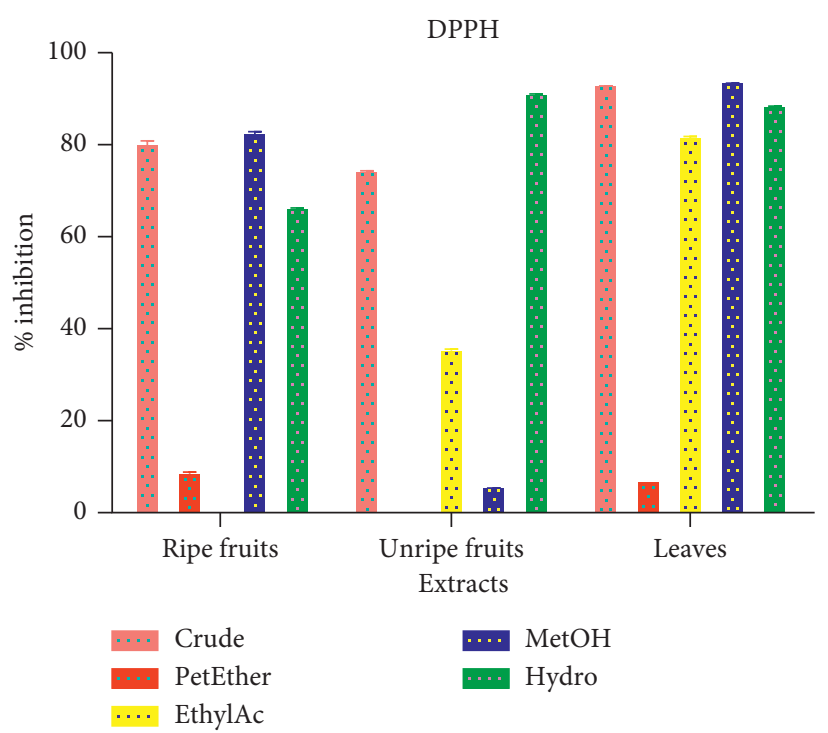

FIGURE 7: The DPPH free radical scavenging activity of $D$. erecta.

enzyme inhibition. It is used to evaluate the free radical mopping capacity of compounds. In this study, the DPPH scavenging activity ranged from $90.0 \%$ to $5.35 \%$ with the leaf showing the highest activity. The high scavenging activity associated with the leaves explain their relevance in traditional medicine. Free radical scavenging is one of the known mechanisms by which antioxidants inhibit lipid peroxidation. This is associated with the activity of antioxidant enzymes such as superoxide dismutase, catalase, and glutathione peroxidase.

From this study (Tables 4-6), the extract/fractions did not show antimicrobial activity against the test organism. This is not consistent with the other previous studies that recorded antimicrobial activity of Duranta erecta against Pseudomonas aeruginosa, Proteus mirabilis, Salmonella typhi, Escherichia coli, and Klebsiella pneumonia. Phytochemicals such as 
TABLE 4: Antimicrobial activity of fractions of ripe fruits against test organisms.

\begin{tabular}{|c|c|c|c|c|c|c|c|c|c|}
\hline Extract & TO 1 & TO 2 & TO 3 & TO 4 & TO 5 & TO 6 & TO 7 & TO 8 & TO 9 \\
\hline Ex 1 & - & - & - & - & - & - & - & - & - \\
\hline Ex 2 & - & - & - & - & - & - & - & - & - \\
\hline Ex 3 & - & - & - & - & - & - & - & - & - \\
\hline Ctrl N & - & - & - & - & - & - & - & - & - \\
\hline Ctrl P & $2.5 \pm .15$ & $2.0 \pm .23$ & $2.3 \pm .17$ & $1.0 \pm .06$ & $1.7 \pm .33$ & $2.6 \pm .10$ & $2.1 \pm .15$ & $1.9 \pm .33$ & $2.2 \pm .41$ \\
\hline
\end{tabular}

Note. TO: test organism; Ex: extract fractions; Ctrl N negative control; Ctrl P positive control; TO 1: Pseudomonas aeroginosa; TO 2: Proteus mirabilis; TO 3: Salmonella typhi; TO 4: Staphylococcus saprohyticus; TO 5: Candida albicans; TO 6: Staphylococcus aureus; TO 7: Escherichia coli; TO 8: Klebsiella pneumonia; TO 9: Paratyphi B; Ex 1: crude extract; Ex 2: hydro fraction; Ex 3: methanol fraction.

Table 5: Antimicrobial activity of fractions of leaves against test organisms.

\begin{tabular}{|c|c|c|c|c|c|c|c|c|c|}
\hline Extract & TO 1 & TO 2 & TO 3 & TO 4 & TO 5 & TO 6 & TO 7 & TO 8 & TO 9 \\
\hline Ex 1 & - & - & - & - & - & - & - & - & - \\
\hline Ex 2 & - & - & - & - & - & - & - & - & - \\
\hline Ex 3 & - & - & - & - & - & - & - & - & - \\
\hline Ctrl N & - & - & - & - & - & - & - & - & - \\
\hline Ctrl P & $2.5 \pm .15$ & $2.0 \pm .23$ & $2.3 \pm .17$ & $1.0 \pm .06$ & $1.7 \pm .33$ & $2.6 \pm .10$ & $2.1 \pm .15$ & $1.9 \pm .33$ & $2.2 \pm .41$ \\
\hline
\end{tabular}

Note. TO: test organism; Ex: extract fractions; Ctrl N negative control; Ctrl P: positive control; TO 1: Pseudomonas aeroginosa; TO 2: Proteus mirabilis; TO 3: Salmonella typhi; TO 4: Staphylococcus saprophyticus; TO 5: Candida albicans; TO 6: Staphylococcus aureus; TO 7: Escherichia coli; TO 8: Klebsiella pneumonia; TO 9: Paratyphi B; Ex 1: crude extract; Ex 2: hydro fraction; Ex 3: methanol fraction.

TABle 6: Antimicrobial activity of fractions of unripe fruits against test organisms.

\begin{tabular}{|c|c|c|c|c|c|c|c|c|c|}
\hline Extract & TO 1 & TO 2 & TO 3 & TO 4 & TO 5 & TO 6 & TO 7 & TO 8 & TO 9 \\
\hline Ex 1 & - & - & - & - & - & - & - & - & - \\
\hline Ex 2 & - & - & - & - & - & - & - & - & - \\
\hline Ex 3 & - & - & - & - & - & - & - & - & - \\
\hline Ctrl N & - & - & - & - & - & - & - & - & - \\
\hline Ctrl P & $2.5 \pm .15$ & $2.0 \pm .23$ & $2.3 \pm .17$ & $1.0 \pm .06$ & $1.7 \pm .33$ & $2.6 \pm .10$ & $2.1 \pm .15$ & $1.9 \pm .33$ & $2.2 \pm .41$ \\
\hline
\end{tabular}

Note. TO: test organism; Ex: extract fractions; Ctrl N: negative control; Ctrl P: positive control; TO 1: Pseudomonas aeroginosa; TO 2: Proteus mirabilis; TO 3: Salmonella typhi; TO 4: Staphylococcus saprophyticus; TO 5: Candida albicans; TO 6: Staphylococcus aureus; TO 7: Escherichia coli; TO 8: Klebsiella pneumonia; TO 9: Paratyphi B; Ex 1: crude extract; Ex 2: hydro fraction; Ex 3: methanol fraction.

flavonoids, triterpenoids, and alkaloids are widely known to exhibit some level of antimicrobial activity against some bacteria [33]. Biological activity of the extract is more effective at higher concentrations, and antimicrobial activity decreases considerably with reduction in the concentration of the extract [22].

\section{Conclusion}

The leaves and fruits of Duranta erecta contained important phytochemicals including flavonoids, phenols, saponins, sterols, tannins, alkaloids, and triterpenoids and minerals such as $\mathrm{Fe}, \mathrm{Zn}$, and $\mathrm{Cu}$ which were within $\mathrm{FAO} / \mathrm{WHO}$ permissible limits. The various parts demonstrated important antioxidant and beneficial properties which are necessary for its usefulness in traditional medicine. The results of FTIR analysis confirmed the presence of alcohols, phenols, alkanes, aldehydes, ketones, aromatics, aliphatic amines, aromatic amines, amides, carboxylic acids, esters, nitro compounds, alkynes, primary and secondary amines, and alkyl halides.

\section{Data Availability}

The data used to support the findings of this study are available from the corresponding author upon request.

\section{Conflicts of Interest}

The authors declare that they have no conflicts of interest.

\section{References}

[1] M. F. Mahomoodally, "Traditional medicines in Africa: an appraisal of ten potent African medicinal plants," EvidenceBased Complementary and Alternative Medicine, vol. 2013, Article ID 617459, 14 pages, 2013.

[2] T. A. Abere, P. E. Okoto, and F. O. Agoreyo, "Antidiarrhoea and toxicological evaluation of the leaf extract of Dissotis rotundifolia Triana (Melastomataceae)," BMC Complementary and Alternative Medicine, vol. 10, no. 1, p. 71, 2010.

[3] C. Larbie, C. Owusu Nyarkoh, and C. Owusu Adjei, "Phytochemical and safety evaluation of hydroethanolic leaf extract of Tecoma stans (L.) juss. ex kunth.," Evidence-Based Complementary and Alternative Medicine, vol. 2019, Article ID 7417624, 12 pages, 2019.

[4] G. A. C. Aymard and J. R. A. Grande, "Duranta neblinensis (Verbenaceae, Duranteae): a new species from Sierra de la Neblina, Amazonas state, Venezuela," Brittonia, vol. 64, no. 3, pp. 246-251, 2012.

[5] S. Hiradate, H. Yada, T. Ishii et al., "Three plant growth inhibiting saponins from Duranta repens," Phytochemistry, vol. 52, no. 7, pp. 1223-1228, 1999.

[6] F. Ijaz, N. Ahmad, I. Ahmad, A. ul Haq, and F. Wang, "Two new anti-plasmodial flavonoid glycosides from 
Durantarepens," Journal of Enzyme Inhibition and Medicinal Chemistry, vol. 25, no. 6, pp. 773-778, 2010.

[7] L. M. Abou-Setta, N. M. Nazif, and A. A. Shahat, "Phytochemical investigation and antiviral activity of Duranta repens," Journal of Applied Sciences Research, vol. 3, pp. 1426-1433, 2007.

[8] K. Bhar, L. K. Kantha, S. Manna, P. Nagalaxmi, K. Eswar, and C. Satya, "In-vitro cytotoxic activity and anthelmintic activity of chloroform extract of D. erecta L. ripe fruits," Research Journal of Pharmaceutical, Biological and Chemical Sciences, vol. 7, no. 6, pp. 860-865, 2016.

[9] A. J. Ekenma, O. D. Ejikene, F. Ekeh, M. Uwagbae, G. Ngwu, and C. Ehilegbu, "Bioefficacy of Duranta erecta extract on yellow fever and dengue vector, Aedes aegypti Linn. in Nigeria," Journal of Medicinal Plants Research, vol. 12, no. 11, pp. 124-132, 2018.

[10] P. Sharma, S. Khandelwal, T. Singh, and R. Vijayvergia, "Phytochemical analysis and antifungal potential of Duranta erecta against some phytopathogenic fungi," International Journal of Pharmaceutical Sciences and Research, vol. 3, pp. 2686-2689, 2012.

[11] J. B. Harborne, Phytochemical Methods: A Guide to Modern Techniques of Plant Analysis, Chapman \& Hall, London, UK, 3rd edition, 1998.

[12] S. Sazada, A. Verma, A. A. Rather, F. Jabeen, and M. K. Meghvansi, "Preliminary phytochemicals analysis of some important medicinal and aromatic plants," Advances in Biological Research, vol. 3, pp. 188-195, 2009.

[13] V. L. Singleton, R. Orthofer, R. M. Lamuela-Raventos, and P. Lester, Methods in Enzymology, Academic Press, Cambridge, MA, USA, 1999.

[14] J. Zhishen, T. Mengcheng, and W. Jianming, "The determination of flavonoid contents in mulberry and their scavenging effects on superoxide radicals," Food Chemistry, vol. 64, no. 4, pp. 555-559, 1999.

[15] I. Oliveira, A. Sousa, I. C. F. R. Ferreira, A. Bento, L. Estevinho, and J. A. Pereira, "Total phenols, antioxidant potential and antimicrobial activity of walnut (Juglans regia L.) green husks," Food and Chemical Toxicology, vol. 46, no. 7, pp. 2326-2331, 2008.

[16] F. C. Mills-Robertson, A. F. Aboakye, G. Duker-Eshun, S. Kaminta, and S. Agbeve, "In vitro antimicrobial activity of Cryptolepis sanguinolenta (Perilocaceae)," African Journal of Pharmacy and Pharmacology, vol. 3, no. 9, pp. 476-480, 2009.

[17] National Centre for Infectious Disease, Centre for Disease Control and Prevention, WHO, Laboratory Methods for the Diagnosis of Epidemic Dysentery and Cholera, Centre for Disease Control and Prevention, Atlanta, Georgia, USA, 199.

[18] A. S. Ogbuagu, K. Okoro, M. U. Akpuaka, J. O. Ogbuagu, U. E. Ekpunobi, and E. C. Ohaekenyem, "Quantitative determination of some secondary metabolites and the antibacterial effects of the leave extracts of Duranta eracta," American Journal of Biomedical Science and Engineering, vol. 1, no. 5, pp. 82-87, 2015.

[19] G. W. Plumb, K. R. Price, and G. Williamson, "Antioxidant properties of flavonol glycosides from green beans," Redox Report, vol. 4, no. 3, pp. 123-127, 1999.

[20] A. L. Souto, J. F. Tavares, M. S. da Silva, M. d. F. F. M. Diniz, P. F. de Athayde-Filho, and J. M. Barbosa Filho, "Anti-inflammatory activity of alkaloids: an update from 2000 to 2010," Molecules, vol. 16, no. 10, pp. 8515-8534, 2011.

[21] Y. Chen, Y. Miao, L. Huang et al., "Antioxidant activities of saponins extracted from Radix trichosanthis: an in vivo and in vitro evaluation," BMC Complementary and Alternative Medicine, vol. 14, no. 1, p. 86, 2014.

[22] FAO/WHO, "Contaminants," in Codex Alimentarius, vol. Volume XVII, 1st edition, 1984.

[23] K. Shirin, S. Imad, S. Shafiq, and K. Fatima, "Determination of major and trace elements in the indigenous medicinal plant Withania somnifera and their possible correlation with therapeutic activity," Journal of Saudi Chemical Society, vol. 14, no. 1, pp. 97-100, 2010.

[24] R. Ullah, J. A. Khader, I. Hussain, N. M. AdElsalam, M. Talha, and N. Khan, "Investigation of macro and micro-nutrients in selected medicinal plants," African Journal of Pharmacy and Pharmacology, vol. 6, no. 25, pp. 1829-1832, 2012.

[25] S. Jabeen, M. T. Shah, S. Khan, and M. Hayat, "Determination of major and trace elements in ten important folk therapeutic plants of Haripur basin, Pakistan," Journal of Medicinal Plants Research, vol. 4, no. 7, pp. 559-566, 2010.

[26] S. M. Dhivya and K. Kalaichelvi, "UV-Vis spectroscopic and FTIR analysis of Sarcostemma brevistigma, wight. and arn," International Journal of Herbal Medicine, vol. 9, no. 3, pp. 46-49, 2017.

[27] N. Rani, S. Sharma, and M. Sharma, "Phytochemical analysis of Meizotropis pellita by FTIR and UV-VIS spectrophotometer," Indian Journal of Science and Technology, vol. 9, no. 31, pp. 1-4, 2016.

[28] S. M. Mohsen and A. S. M. Ammar, "Total phenolic contents and antioxidant activity of corn tassel extracts," Food Chemistry, vol. 112, no. 3, pp. 595-598, 2008.

[29] S. K. Sharma and A. P. Singh, "In vitro antioxidant and free radical scavenging activity of Nardostachys jatamansi DC.," Journal of Acupuncture and Meridian Studies, vol. 5, no. 3, pp. 112-118, 2012.

[30] M. S. Stankovic, M. D. Topuzovic, S. Solujic, and V. Mihailovi, "Antioxidant activity and concentration of phenols and flavonoids in the whole plant and plant parts of Teucrium chamaerdys L. var. glandiferum Haussk," Journal of Medicinal Plants Research, vol. 4, no. 20, pp. 2092-2098, 2010.

[31] E. dos Santos, M. Pereira, C. da Silva et al., "Antibacterial activity of the alkaloid-enriched extract from Prosopis juliflora pods and its influence on in vitro ruminal digestion," International Journal of Molecular Sciences, vol. 14, no. 4, pp. 8496-8516, 2013.

[32] M. J. Bangou, N. T. R. Méda, A. M. E. Thiombiano et al., "Antioxidant and antibacterial activities of five Verbenaceae species from Burkina Faso," Current Research Journal of Biological Sciences, vol. 4, no. 6, pp. 665-672, 2012.

[33] C. D. Romero, S. F. Chopin, G. Buck, E. Martinez, M. Garcia, and L. Bixby, "Antibacterial properties of common herbal remedies of the Southwest," Journal of Ethnopharmacology, vol. 99, no. 2, pp. 253-257, 2005. 


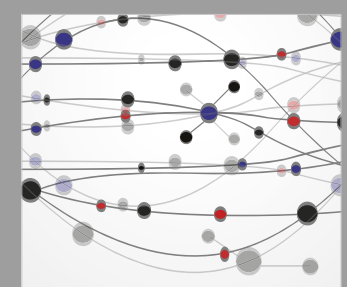

The Scientific World Journal
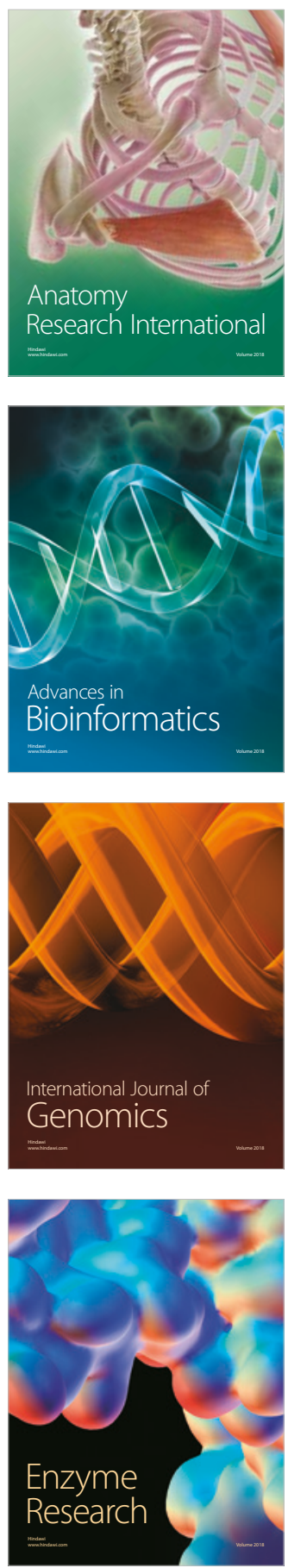
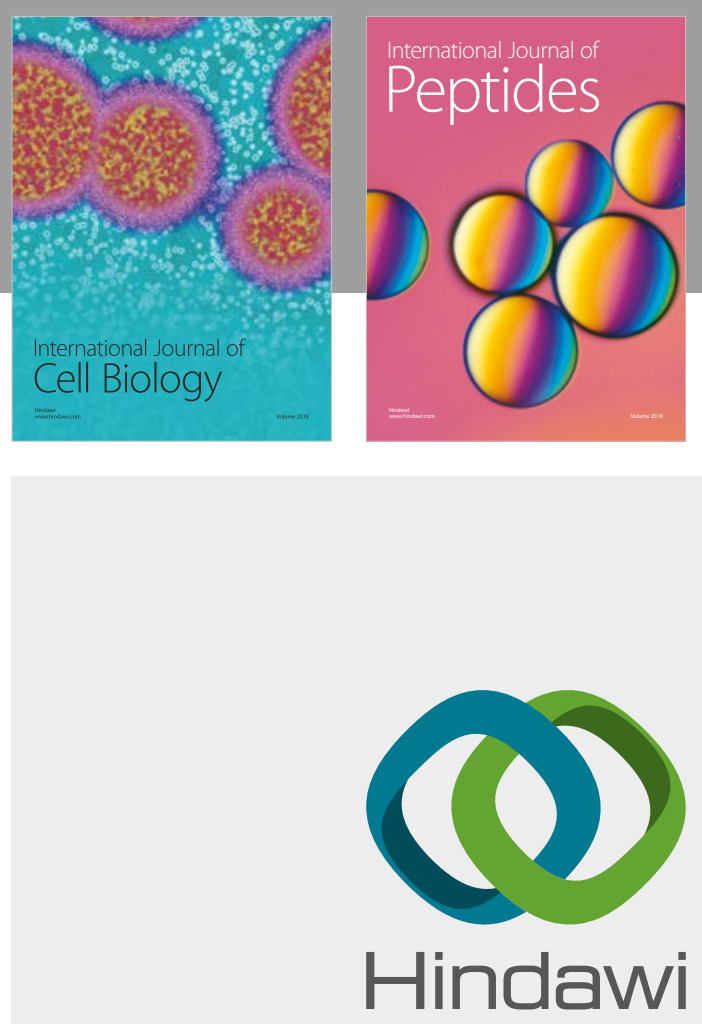

Submit your manuscripts at

www.hindawi.com
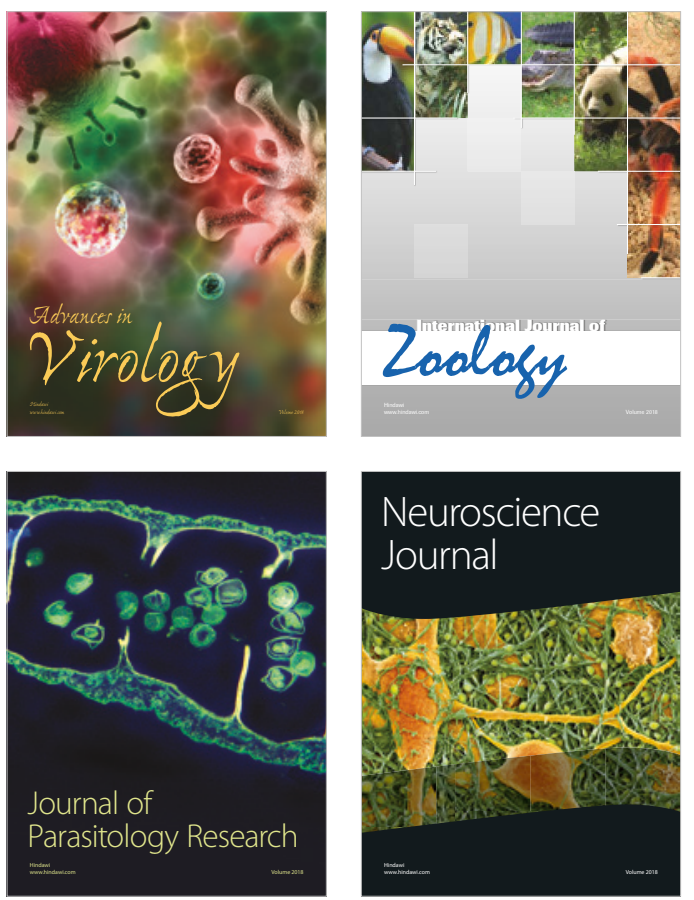
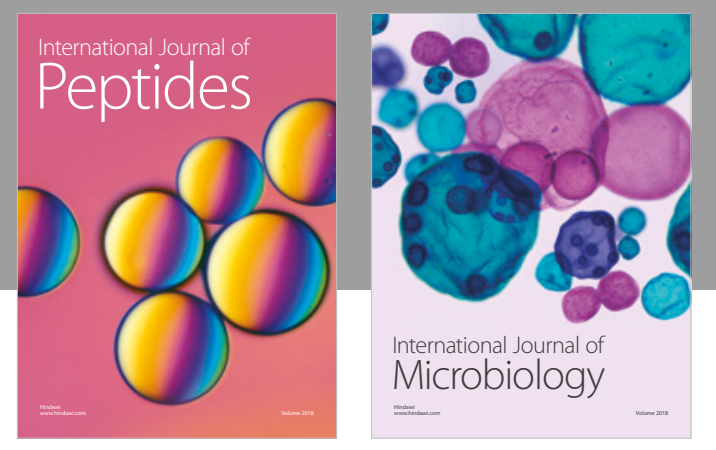

nternational Journal of Microbiology
Journal of
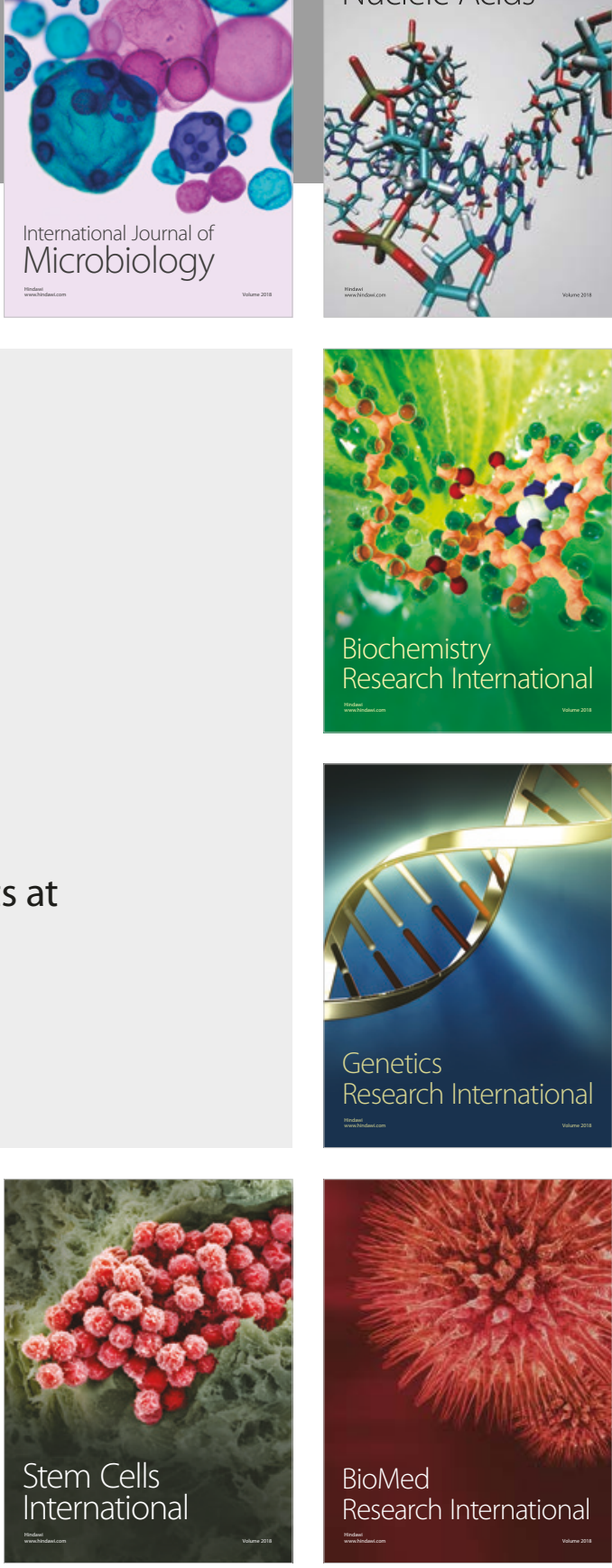
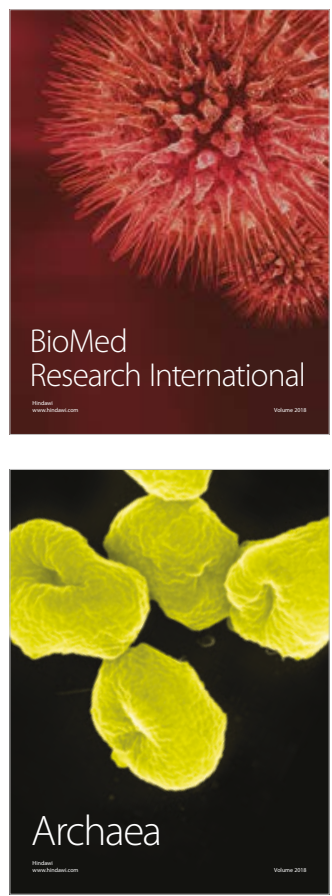